\title{
Reduction of air leaks in a canine model of pulmonary resection with a new staple-line buttress
}

\author{
Ayumi Hashimoto, MS, ${ }^{a}$ Masaki Kuwabara, MD, PhD, ${ }^{a}$ Yoshinori Hirasaki, MD,, a,b,c \\ Hiroyuki Tsujimoto, MD, PhD, ${ }^{\mathrm{a}}$ Tsuyoshi Torii, $\mathrm{MD}, \mathrm{PhD},{ }^{\mathrm{a}}$ Tatsuo Nakamura, $\mathrm{MD}, \mathrm{PhD},{ }^{\mathrm{c}}$ and \\ Akeo Hagiwara, $\mathrm{MD}, \mathrm{PhD}^{\mathrm{a}}$
}

\begin{abstract}
Objective: Recently, linear staplers have been used frequently in thoracic surgery; however, air leakage from the staple line is still unresolved. Various buttress materials have been developed to prevent air leakage, but performance is still not satisfactory. We are therefore developing a new material, consisting of calcium alginate nonwoven fabric covered with sodium alginate sponge.
\end{abstract}

\begin{abstract}
Methods: Thirty-three beagle dogs were divided into 7 groups, and each underwent thoracotomy. Right middle lobe incision was performed with a linear stapler and 1 of the following buttress methods: group A, no buttress; group $\mathrm{B}$, polyglycolic acid nonwoven fabric; group $\mathrm{C}$, fibrin glue alone; group $\mathrm{D}$, polyglycolic acid nonwoven fabric with fibrin glue; group E, polyglycomer sheet; group F, new alginate material; and group G, polyglycolic acid nonwoven fabric plus new alginate material. Burst pressures were measured under mechanical ventilation management.
\end{abstract}

Results: Burst pressures were $12.0 \pm 6.8 \mathrm{~cm} \mathrm{H}_{2} \mathrm{O}$ in group $\mathrm{A}, 31.3 \pm 6.6 \mathrm{~cm} \mathrm{H}_{2} \mathrm{O}$ in group $\mathrm{B}, 13.9 \pm 3.8 \mathrm{~cm} \mathrm{H}_{2} \mathrm{O}$ in group $\mathrm{C}, 26.9 \pm 2.8 \mathrm{~cm} \mathrm{H}_{2} \mathrm{O}$ in group $\mathrm{D}, 24.8 \pm 1.8 \mathrm{~cm} \mathrm{H}_{2} \mathrm{O}$ in group $\mathrm{E}, 48.5 \pm 4.9 \mathrm{~cm} \mathrm{H}_{2} \mathrm{O}$ in group $\mathrm{F}$, and $54.2 \pm 12.4 \mathrm{~cm} \mathrm{H}_{2} \mathrm{O}$ in group $\mathrm{G}$. $\mathrm{F}$ and $\mathrm{G}$ group pressures reached the target of 40 to $50 \mathrm{~cm} \mathrm{H}_{2} \mathrm{O}$ and were significantly higher than those of the 5 conventional groups $(P<.0005)$

Conclusions: This alginate buttress should be effective for preventing air leakage during operations because it has both sealant and bolster effects working in conjunction. (J Thorac Cardiovasc Surg 2011;142:366-71)

The aim of this experiment was to develop a new buttress material to prevent air leakage from the staple line during operations. The linear stapler is an indispensable tool in thoracic operations. ${ }^{1}$ It sutures the lung tissue with fine wire staples, which are harder and more rigid than the fragile lung tissue. When the lung is inflated, the staples often tear the lung, and air leakage occurs from the enlarged pinholes formed by the staples. Droghetti and colleagues ${ }^{2}$ reported an incidence of air leakage at the staples during operation of $90 \%$. Such air leakage increases the risk of serious postoperative complications, such as pneumothorax. ${ }^{3}$ This in turn may delay the removal of chest drainage tubes ${ }^{4}$ and prolong hospital stay. ${ }^{5}$

A variety of reinforcement materials have been proposed to control and prevent air leakage. ${ }^{4-8}$ They can be classified as sealants and bolsters. Singhal and Shrager ${ }^{9}$ reviewed

From Medical Life System, ${ }^{a}$ Faculty of Life and Medical Science, Doshisha

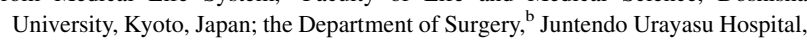
Juntendo University, Tokyo, Japan; and the Institute for Frontier Medical Sciences, ${ }^{\mathrm{c}}$ Kyoto University, Kyoto, Japan.

Disclosures: Authors have nothing to disclose with regard to commercial support.

Received for publication Nov 11, 2010; revisions received April 13, 2011; accepted for publication May 5, 2011; available ahead of print June 13, 2011.

Address for reprints: Ayumi Hashimoto, MS, Medical Life System, Faculty of Life and Medical Science, Institute for Doshisha University, Tataramiyakodani 1-3, Kyotanabe, Kyoto, 610-0394, Japan (E-mail: aayumihashimoto@gmail.com). $0022-5223 / \$ 36.00$

Copyright $\subset 2011$ by The American Association for Thoracic Surgery doi: $10.1016 /$ j.jtcvs.2011.05.001 currently available reinforcement materials and made 2 observations. (1) Buttresses have been shown to reduce the incidence of air leakage and to shorten the duration of chest tube drainage and hospital stays with their bolster effect. (2) For liquid sealants, most studies have reported neither statistically nor clinically significant improvements in postoperative air leakage, duration of chest tube drainage, or hospital stay, although some reports have demonstrated sealants to prevent postoperative air leakage by covering the staple line.

We tried to develop a new buttress material that has both of these sealant and bolster effects working in conjunction. In this first report, the performance of the new buttress was examined in terms of burst pressure during operations on dogs, and this was compared with the performance of other conventional materials.

\section{MATERIALS AND METHODS}

\section{Preparation of the New Alginate Buttress}

The new buttress has 2 components. The exterior layers are sodium alginate sponge, and the central layer is calcium alginate nonwoven fabric (Figure 1), which function as sealant and bolster, respectively. Sodium alginate (Wako Pure Chemical Industries, Ltd, Osaka, Japan) was dissolved in distilled water to $2 \%$ (weight/volume). A sheet $(3.5 \times 7 \mathrm{~cm})$ of calcium alginate nonwoven fabric (Kaltostat; ConvaTec, Inc, Skillman, NJ), already in clinical use as a wound dressing, was dipped in this sodium alginate solution for 30 seconds. This caused the sodium alginate to change into calcium alginate gel at the marginal area, forming a sodium alginatecalcium alginate mixture. This complex was then freeze-dried (freezing 


\section{Abbreviation and Acronym \\ PGA = polyglycolic acid}

at $-80^{\circ} \mathrm{C}$ for 12 hours and drying at $-50^{\circ} \mathrm{C}$ for 12 hours), resulting in the alginate buttress material. The alginate buttress has 3 layers. The midline layer (width $1 \mathrm{~mm}$ ) of calcium alginate nonwoven fabric (fiber diameter $10 \mu \mathrm{m})$ was observed by scanning electron microscope (S-2-2380N; Hitachi, Ltd, Tokyo, Japan). Honeycomb structure layers (width $0.7 \mathrm{~mm}$ ) of sodium alginate sponge were observed on both sides of the midline layer.

\section{Animal Experiment}

Forty-two beagle dogs (female, 1-2 years old, weighing 9-11 kg) were assigned at random to 7 groups of 6 dogs. For each group, no buttress or 1 of 6 different buttresses was applied. During the experiment, however, measurements could not be taken from 1 dog each in groups $\mathrm{A}, \mathrm{B}, \mathrm{E}$, and $\mathrm{F}$ because the lung tissue was damaged before stapling or air leakage appeared outside the zone of the staple line. This resulted in groups A, B, E, and F having 5 dogs each, whereas groups $\mathrm{C}, \mathrm{D}$, and $\mathrm{G}$ continued to have 6 dogs each.

With the dogs under general anesthesia with intravenous pentobarbital sodium ( $25-30 \mathrm{mg} / \mathrm{kg}$ intravenously), the animals were placed in a dorsal decubitus position. After endotracheal intubation, a right-sided thoracotomy was performed under mechanical ventilation, and the right lung was exposed.

An incision was made on the right middle lobe with a linear stapler. To do this, airway pressure was maintained at $20 \mathrm{~cm} \mathrm{H}_{2} \mathrm{O}$ for 2 minutes to ensure sufficient expansion of the lung. Then the jaws of the linear stapler (for groups A, B, C, D, F, and G, ENDO-GIA Universal Straight R 60: Covidien, Mansfield, Mass; and for group E, Duet TRS 60; Covidien) were positioned on the right middle lobe over a $5.5-\mathrm{cm}$ length from the peripheral towards the hilum. Next, an air circuit pop-off valve on the ventilator was opened so that the airway pressure could be freely changed according to the condition of the lung. After this, at an endotracheal pressure of $10 \mathrm{~cm} \mathrm{H}_{2} \mathrm{O}$, at which the lung was still expanded, the jaws of the linear stapler were closed and clamped for 10 seconds, making an incision of approximately $5.5 \mathrm{~cm}$ from the periphery toward the hilum. Both edges of the incision were stapled with 1 of the 7 different methods described here.

For group A, the lung was simply cut with the linear stapler (Figure 2, A). For group B, polyglycolic acid (PGA) nonwoven fabric ( $0.1 \mathrm{~mm}$ thick, 1 ply; Gunze Ltd, Kyoto, Japan) was used as suture reinforcement (Figure 2, B). For group $\mathrm{C}, 2 \mathrm{~mL}$ of fibrin glue sealant (Beriplast $\mathrm{P}$ Combi-Set; CSL Behring, Inc, King of Prussia, Pa) was delivered by a pressurized aerosol spray over the staple closure. To be precise, both $1 \mathrm{~mL}$ of fibrinogen and $1 \mathrm{~mL}$ of thrombin solution were sprayed as a mixed aerosol with the Beriplast P Combi-Set application system (Figure 2, C). For group $\mathrm{D}$, after stapling with a PGA nonwoven fabric, fibrin glue sealant was applied in the same manner as for group C (Figure 2,D). For group E, the lung was simply cut with the Duet TRS linear stapler with its preattached polyglycomer sheet, (Figure 2, E). For group F, the new alginate buttress was placed on both sides of the lung surface like a sandwich along the cutting line (Figure $3, A$ ). The lung tissue, together with the alginate buttress, was stapled and cut (Figure 3, B). Then, $2 \mathrm{~mL}$ of $0.6 \%$ calcium gluconate solution (Wako Pure Chemical Industries) was applied over the buttress (Figures 2, $F$ and 3, $C$ ). For group $\mathrm{G}$, the alginate buttress was first placed on both sides of the cutting line. Then PGA nonwoven fabric sleeves were mounted on the linear stapler, and the lung tissue and the alginate buttress were stapled together with PGA sleeves and cut. The calcium gluconate solution $(2 \mathrm{~mL})$ was applied over the buttress with the same method used for group F (Figure 2, G).

Three minutes (groups $\mathrm{C}$ and D) or 30 seconds (groups A, B, E, F, and G) after the previously described procedures, the airway pressure was raised manually with a bag ventilator at a rate of $0.67 \mathrm{~cm} \mathrm{H}_{2} \mathrm{O} / \mathrm{s}$ from 10 $\mathrm{cm}_{2} \mathrm{O}$ until air leakage was detected at the stapled area.

The burst pressure was defined as the airway pressure at which air leakage began. To determine the presence of air leakage from the staple line, saline solution containing $1 \%$ neutral detergent was poured on the stapled area. With this method, air leakage was clearly visualized by bubble formation.

This animal experiment was approved in advance by the institutional animal care and use committee of Doshisha University.

\section{Statistical Analyses}

The data shown represent mean \pm SD. Because of the small number of animals, we applied the following 2-step procedure to avoid multiplicity issues. In step 1, to examine the experiment's sensitivity, the no-buttress group (group A) and the conventional method groups (groups B, C, D, and E) were compared. In step 2, after the comparison in step 1 confirmed that a significant difference existed, the new buttress material groups (groups F and G) and the conventional method groups were compared For both steps, the Dunnett test (2-sided) was used to compare different treatments.

\section{RESULTS \\ Effect of the Buttress}

The burst pressures of each group are shown in Figure 4. The burst pressure of group $\mathrm{G}$ was $54.2 \pm 12.4 \mathrm{~cm} \mathrm{H}_{2} \mathrm{O}$, and that of group $\mathrm{F}$ was $48.5 \pm 4.9 \mathrm{~cm} \mathrm{H}_{2} \mathrm{O}$. The results of the other groups were $31.3 \pm 6.6 \mathrm{~cm} \mathrm{H}_{2} \mathrm{O}$ for group $\mathrm{B}, 23.9 \pm$ $3.8 \mathrm{~cm} \mathrm{H}_{2} \mathrm{O}$ for group $\mathrm{C}, 26.9 \pm 2.7 \mathrm{~cm} \mathrm{H}_{2} \mathrm{O}$ for group $\mathrm{D}$, $24.8 \pm 1.8 \mathrm{~cm} \mathrm{H}_{2} \mathrm{O}$ for group $\mathrm{E}$, and $12 \pm 6.8 \mathrm{~cm} \mathrm{H}_{2} \mathrm{O}$ for group A. In statistical analysis step 1, the burst pressures of groups $\mathrm{B}, \mathrm{C}, \mathrm{D}$, and $\mathrm{E}$ were significantly higher than that of group A $(P<.0005$ to $P<.005)$. In step 2 , the burst pressures of groups $\mathrm{F}$ and $\mathrm{G}$ were significantly higher than those of groups $\mathrm{B}, \mathrm{C}, \mathrm{D}$, and $\mathrm{E}(P<.0005$ for all).

We examined carefully how air leakage occurred at the stapling site. For groups $\mathrm{C}$ and $\mathrm{D}$, air bubbles appeared from the deep end of the cutting margin or pinholes formed by the staples. They pushed up the fibrin glue layer on the lung tissue and peeled it off. Once the fibrin glue had peeled off, it did not reattach to the lung tissue during the operation. For group A, air leakage appeared from both the deep end of the cutting margin and pinholes formed by the staples. For the other groups, air leakage appeared from the deep end of the cutting margins.

\section{DISCUSSION}

Several randomized studies have demonstrated that conventional sealants (BioGlue, ${ }^{10}$ Vivostat,${ }^{8}$ Coseal, ${ }^{11}$ TachoSil, ${ }^{12}$ PleuraSeal,${ }^{13}$ and fibrin glue ${ }^{14}$ ) and buttresses ( $\mathrm{PGA},{ }^{15}$ bovine pericardium, ${ }^{16}$ and expanded polytetrafluoroethylene ${ }^{17}$ ) result in improvements in postoperative air leakage, duration of chest tube drainage, and hospital stay.

During positive end-expiratory pressure ventilation, even in cases of acute respiratory distress syndrome, the inspiratory driving pressure of 20 to $24 \mathrm{~cm} \mathrm{H}_{2} \mathrm{O}$ is a marking point to protect the lung from barotrauma, ${ }^{18}$ because the 


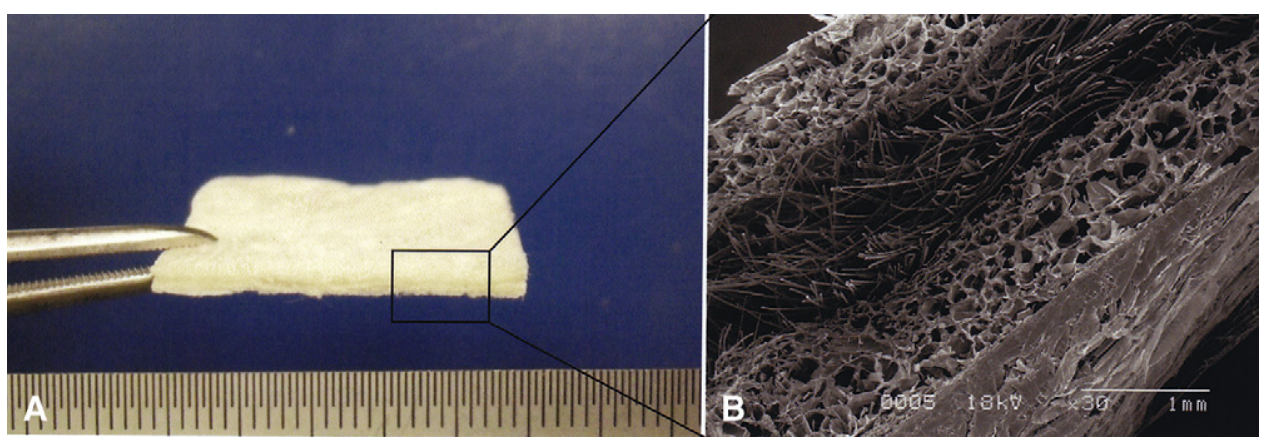

FIGURE 1. A vertical cross-sectional view of the alginate buttress. A, Macroscopic view. B, Scanning electron microscopic view. The exterior layers are made from sodium alginate sponge. The central layer is made from calcium alginate nonwoven fabric. The alginate buttress has 3 layers. The midline layer (width, $1 \mathrm{~mm}$ ) of calcium alginate nonwoven fabric (fiber diameter, $10 \mu \mathrm{m}$ ) was observed by scanning electron microscope (S-2-2380N; Hitachi, Ltd, Tokyo, Japan). Honeycomb structure layer (width, $70 \mu \mathrm{m}$ ) of sodium alginate sponge was observed on both sides of the midline layer.

physiologic range of airway pressure is less than $25 \mathrm{~cm}$ $\mathrm{H}_{2} \mathrm{O}$. During general anesthesia for operations, the upper limit of the airway pressure is set at 20 to $25 \mathrm{~cm} \mathrm{H}_{2} \mathrm{O}$ to prevent barotrauma. It is therefore necessary for the reinforced staple line to withstand an airway pressure of at least 20 to $25 \mathrm{~cm} \mathrm{H}_{2} \mathrm{O}$ to prevent air leakage. We found that for group A, the burst pressure of the staple line without any buttress, which was significantly lower than in any of the other groups, was also lower than the safe level of 20 to $25 \mathrm{~cm}$ $\mathrm{H}_{2} \mathrm{O}$.

Roberson and colleagues ${ }^{17}$ compared the effectiveness of stapling with pericardium or expanded polytetrafluoroethylene with that of stapling alone in prevention of air leakage in dogs. The use of these buttresses increased the burst pressure 9.6 to $11.8 \mathrm{~cm} \mathrm{H}_{2} \mathrm{O}$ beyond that of staples alone. If we apply this increase to the data obtained for no buttress in our experiment, it suggests that a buttress made of expanded polytetrafluoroethylene or bovine pericardium would have withstood an airway pressure up to 21.6 to $28.8 \mathrm{~cm} \mathrm{H}_{2} \mathrm{O}$. Many conventional buttresses withstand pressures in the range of 20 to $25 \mathrm{~cm} \mathrm{H}_{2} \mathrm{O}$.

Kawamura and associates' report ${ }^{19}$ described a staple line reinforced with PGA nonwoven fabric as capable of withstanding an airway pressure of $20 \mathrm{~cm} \mathrm{H}_{2} \mathrm{O}$ but observed air leakage after severe coughing, which increases airway pressure. In the postoperative period, the airway pressure will sometimes increase to higher levels as a result of coughing.

With a protective ventilation strategy during positive end-expiratory pressure ventilation, the peak airway pressure is restricted to $40 \mathrm{~cm} \mathrm{H}_{2} \mathrm{O}$ to protect the alveoli from barotrauma. ${ }^{17}$ Furthermore, the incidence of barotrauma is low when peak pressure is kept below $50 \mathrm{~cm} \mathrm{H}_{2} \mathrm{O}$. In this experiment, we therefore decided on an upper target pressure of 40 to $50 \mathrm{~cm} \mathrm{H}_{2} \mathrm{O}$.

The burst pressures for groups $\mathrm{G}$ and $\mathrm{F}$ were both higher than 40 to $50 \mathrm{~cm} \mathrm{H}_{2} \mathrm{O}$. In contrast, the burst pressures of the other groups (A, B, C, D, and E) were lower than $40 \mathrm{~cm}$ $\mathrm{H}_{2} \mathrm{O}$. These results indicate that application of the alginate buttress enables the staple line to withstand an airway pressure level at which barotrauma occurs.

Let us now consider why the burst pressures of the groups with the alginate buttress (groups $F$ and $\mathrm{G}$ ) exceeded those of the other groups. When the new buttress material is placed on the lung, the exterior layer (the dry spongeform sodium alginate) absorbs fluid on the lung and changes into a fluid gel with low viscosity. This fluid gel fills and covers the enlarged pinholes formed by the staples; it also penetrates into the central layer (calcium alginate nonwoven fabric). This alone, however, would not prevent air leakage because the viscosity is too low.

Sodium alginate is a water-soluble polymer that is bioabsorbable ${ }^{20}$ and has high biocompatibility. ${ }^{21}$ It is also ionically cross-linkable by exchanging sodium ions for calcium ions, which bind neighboring alginate polymer chains. ${ }^{21}$ The addition of calcium ions thus changes the fluid sodium alginate gel to a firm calcium alginate gel that can act as a sealant. In wet conditions, the central layer of the new buttress absorbs 15 to 20 times its own weight in water and swells. This swollen central layer acts not only as a bolster but also as a calcium ion provider. The calcium ions in the calcium alginate fibers, which are necessary for fiber formation in the production process, are replaced by sodium ions when placed in contact with body fluids. ${ }^{22}$ The calcium ions released by this process partially change the low viscosity sodium alginate gel into a firm but flexible calcium alginate gel that both plugs and seals the pinholes. In this experiment, calcium gluconate solution was sprayed over the preparation to enhance this reaction. Thus our new buttress has both sealant and bolster effects and is more effective than conventional reinforcement materials because of the collaboration of these effects. This might explain why the burst pressures of groups $F$ and $G$ were sufficiently high. 


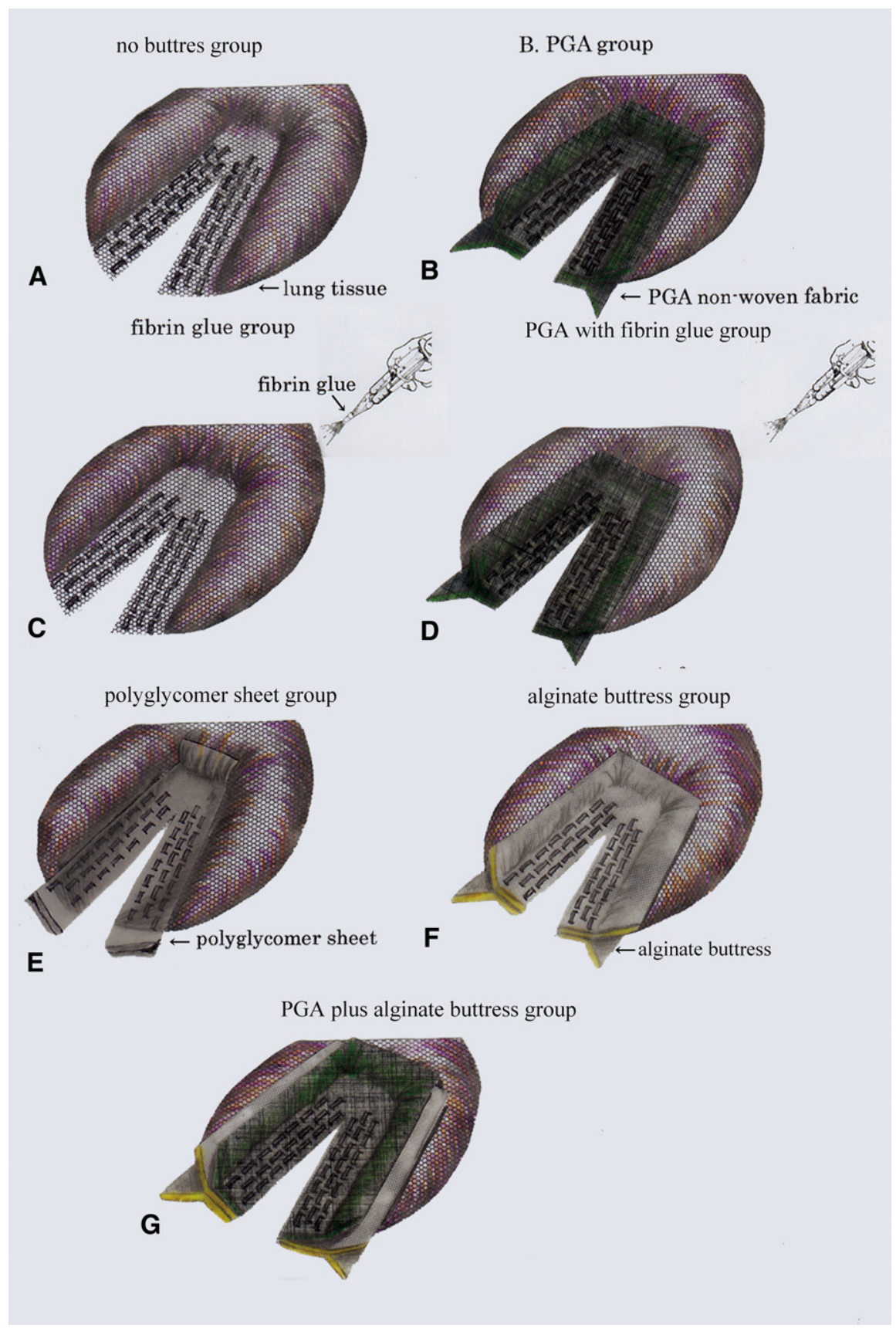

FIGURE 2. Procedure of experiment. A, No buttress group. Only the linear stapler (no buttress material) was used to suture and cut the lung tissue. B, Polyglycolic acid (PGA) group. A linear stapler with its jaws covered with polyglycolic acid nonwoven fabric was used to suture and cut the lung tissue. C, Fibrin glue group. The linear stapler was used without any buttress material. Then, after the lung tissue had been sutured and cut, the stapled area was sprayed with fibrin glue to seal the stapled closure. D, Polyglycolic acid with fibrin glue group. Polyglycolic acid nonwoven fabric was attached to the jaws of the linear stapler, and the lung tissue was sutured and cut. The stapled area was then sprayed with fibrin glue to seal the stapled closure. E, Polyglycomer sheet group. A linear stapler with attached polyglycomer sheet (Duet TRS; Covidien, Mansfield, Mass) was used to suture and cut the lung tissue. F, Alginate buttress material group. The alginate buttress material was placed on both sides of the cutting line on the lung tissue. The lung tissue, together with the alginate buttress material, was then sutured and cut. After cutting, the stapled area was sprayed with calcium gluconate solution, which changed the sodium alginate fluid gel to a firm gel, to seal the stapled area. G, Polyglycolic acid plus alginate buttress material group. The alginate buttress material was placed on the lung tissue, the polyglycolic acid nonwoven fabric was attached to the linear stapler, and the lung tissue was sutured and cut. After cutting, the stapled area was sprayed with calcium gluconate solution, which changed the sodium alginate fluid gel to a firm gel, to seal the stapled area. 

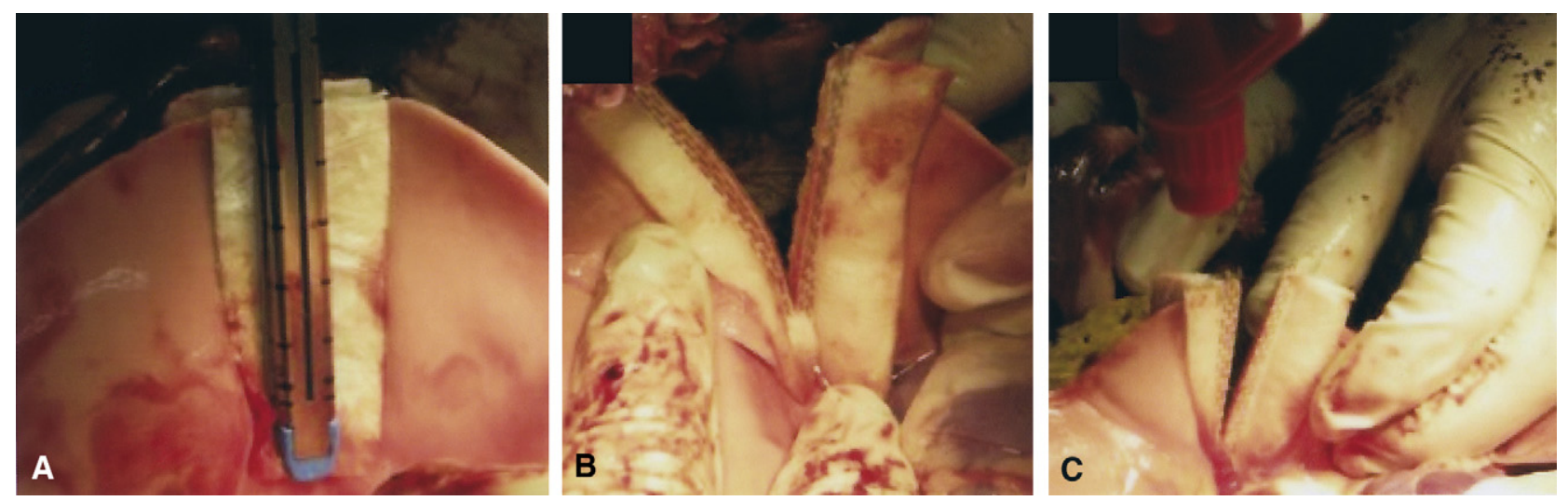

FIGURE 3. Picture of the procedure for the alginate buttress group. A, The new alginate buttress was placed on both sides of the lung surface, like a sandwich, along the cutting line. B, The lung tissue and the alginate buttress were together stapled and cut. C, The calcium gluconate solution was then applied over the buttress.

We can also explain the higher variability in results for group G. Because the new buttress material and PGA are separate materials, they did not always fit well together. It is thought that this resulted in their effects working individually but without any additive effect. When a good fit between the separate materials was achieved, however, in

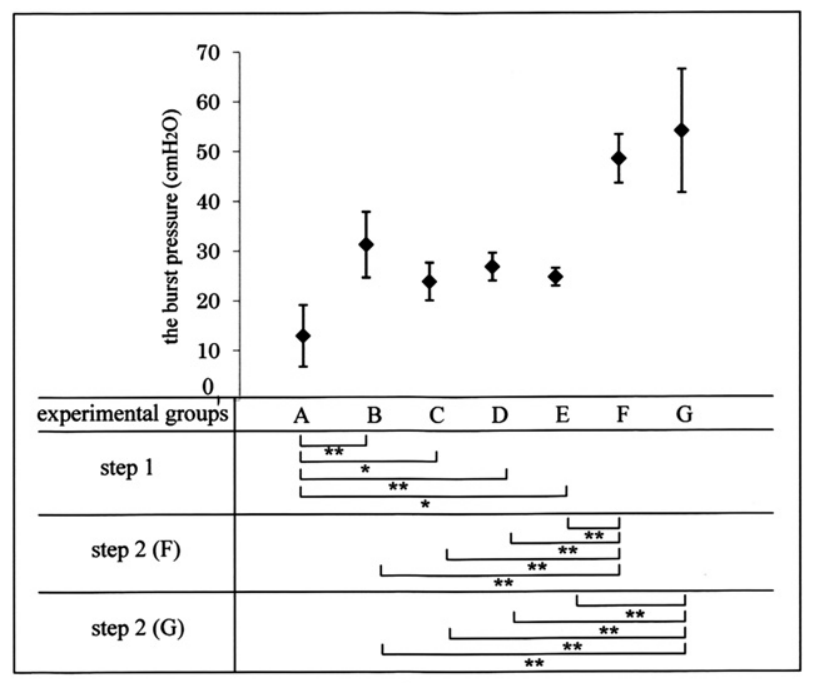

$\checkmark$ : mean, bar indicates standard deviation

${ }^{*}: \mathrm{p}<0.005,{ }^{* *}: \mathrm{p}<0.0005$

FIGURE 4. Burst pressures for each experimental group. The burst pressure was defined as the pressure at which air leakage started to occur. To reduce the number of analyses and avoid multiplicity issues, we applied the Dunnett test with the following 2-step procedure. In step 1, the no buttress group was compared with the conventional method groups to check assay sensitivity. In step 2, after checking that the conventional group was superior to the no buttress group in step 1, the new buttress material groups were compared with the conventional method groups (group F vs groups $\mathrm{B}, \mathrm{C}, \mathrm{D}$, and $\mathrm{E}$; group $\mathrm{G}$ vs groups $\mathrm{B}, \mathrm{C}, \mathrm{D}$, and $\mathrm{E}$ ). $A$, No buttress material; $B$, polyglycolic acid alone; $C$, fibrin glue alone; $D$, polyglycolic acid with fibrin glue; $E$, polyglycomer sheet; $F$, alginate buttress material; $G$, polyglycolic acid plus alginate buttress material. addition to the individual effects an additive effect occurred, resulting in higher values. So we believe that the use of 2 separate materials resulted in the higher variability.

Before performing this experiment, we expected that the results for group D (PGA nonwoven fabric with fibrin glue) would be better than those for group B (PGA nonwoven fabric alone) and group $\mathrm{C}$ (fibrin glue alone). Contrary to our expectations, the result for group B was higher than that for group D. Two possible reasons for this are considered. (1) For group D, after the PGA nonwoven fabric was stapled and cut along the staple line, fibrin glue was sprayed over the stapled area. Because PGA nonwoven fabric is a hydrophobic material, however, the sprayed fibrin glue adhered irregularly to the PGA fabric, making an inhomogeneous layer of glue and resulting in a lower burst pressure. (2) The fibrin glue was sprayed over the stapled area when the airway pressure was $10 \mathrm{~cm} \mathrm{H}_{2} \mathrm{O}$. After the fibrin glue had coagulated, the airway pressure was then increased slowly to inflate the lung, but because the fibrin glue had insufficient adhesion strength or flexibility, it peeled away from the stapled area. As a result no cumulative effect was observed for the PGA nonwoven fabric and fibrin glue combination in group D. In contrast, the combination of PGA nonwoven fabric and new alginate material in group $\mathrm{G}$ did produce a significantly higher burst pressure. We believe that the flexibility of the alginate gel allowed it to be more effective for groups $\mathrm{F}$ and $\mathrm{G}$ than fibrin glue was for groups $\mathrm{C}$ and $\mathrm{D}$.

With regard to clinical risks associated with the new buttress, it was made only with materials that are already commercially available as surgical materials or clinical drugs and thus could be guaranteed to be safe and so enter easily into clinical use. Calcium gluconate has been used clinically as an intravenous medium (Calcicol). Calcium alginate nonwoven fabric has been used as a wound dressing (Kaltostat). Blair and coworkers ${ }^{23}$ reported that Kaltostat implanted in the body was reabsorbed within 3 months. ${ }^{23}$ 
Sodium alginate has been used clinically as a topical hemostatic agent (Alto), and an antiulcer drug (Alroid-G).

In terms of safety from viral infection, alginate is preferable to fibrin glue or bovine pericardium because viral and prion infections cannot be transmitted from plants to animals. ${ }^{24}$ Sodium alginate, which is extracted from marine algae, is classified as "generally recognized as safe" because of its low risk of viral infection for human beings. This contrasts well with the viral infection risks posed by fibrin glue and bovine pericardium. ${ }^{25}$

In the conclusion, the results of this experiment suggest that the new buttress could have a superior efficacy to prevent air leakage from the staple line. These studies have, however, evaluated the performance of each buttress only in terms of burst pressure of the staple line during operation. To achieve a more complete evaluation of the buttress, further studies will be necessary. First, the long-term prevention of air leakage after surgery, chest tube removal time, duration of hospital stay, and associated histologic changes should be examined, because air leakage also occurs postoperatively. Further evaluation of efficacy and safety should also be performed. In addition, the utility of this buttress in patients with emphysema should be evaluated clinically, because in this animal experiment the performance was evaluated in healthy (nonemphysematous) lungs.

We thank Dr Yuki Ozamoto, Ayumi Tanzawa, and Mari Matoba of Doshisha University for their cooperation in this study and their advice about the actual research. We also thank the doctors of the Institute of Frontier Medical Sciences at Kyoto University. Furthermore, we thank Drs Hiroshi Yadohisa and Takashi Omori for their assistance with the statistical analysis of the data.

\section{References}

1. McKenna RJ Jr, Brenner M, Gelb AF, Mullin M, Singh N, Peters H, et al. A randomized, prospective trial of stapled lung reduction versus laser bullectomy for diffuse emphysema. J Thorac Cardiovasc Surg. 1996;111:317-22.

2. Droghetti A, Schiavini A, Muriana P, Folloni A, Picarone M, Bonadiman C, et al. A prospective randomized trial comparing completion technique of fissures for lobectomy: stapler versus precision dissection and sealant. J Thorac Cardiovasc Surg. 2008;136:383-91.

3. Ferguson MK, Gaissert HA, Grab JD, Sheng S. Pulmonary complications after lung resection in the absence of chronic obstructive pulmonary disease: the predictive role of diffusing capacity. J Thorac Cardiovasc Surg. 2009;138: 1297-302.

4. Macchiarini P, Wain J, Almy S, Dartevelle P. Experimental and clinical evaluation of a new synthetic, absorbable sealant to reduce air leaks in thoracic operations. J Thorac Cardiovasc Surg. 1999;117:751-8.
5. Venuta F, Rendina EA, De Giacomo T, Flaishman I, Guarino E, Ciccone AM, et al. Technique to reduce air leaks after pulmonary lobectomy. Eur J Cardiothorac Surg. 1998;13:361-4.

6. Takanami I, Yamamoto Y, Yamamoto T, Kodaira S. A technique to minimize air leakage after excision of emphysematous bulla of the lungs. J Thorac Cardiovasc Surg. 1995;110:547-8.

7. Downey DM, Michel M, Harre JG, Pratt JW. Functional assessment of a new staple line reinforcement in lung resection. J Surg Res. 2006;131:49-52.

8. Moser C, Opitz I, Znai W, Rousson V, Russi EW, Weder W, et al. Autologous fibrin sealant reduces the incidence of prolonged air leak and duration of chest tube drainage after lung volume reduction surgery: a prospective randomized blinded study. J Thorac Cardiovasc Surg. 2008;136:843-9.

9. Singhal S, Shrager JB. Should buttresses and sealants be used to manage pulmonary parenchymal air leaks? J Thorac Cardiovasc Surg. 2010;140:1220-5.

10. Tansley P, Al-Mulhim F, Lim E, Ladas G, Goldstraw P. A prospective, randomized, controlled trial of the effectiveness of BioGlue in treating alveolar air leaks. $J$ Thorac Cardiovasc Surg. 2006;132:105-12.

11. Venuta F, Diso D, De Giacomo T, Anile M, Rendina EA, Coloni GF. Use of a polymeric sealant to reduce air leaks after lobectomy. $J$ Thorac Cardiovasc Surg. 2006;132:422-3.

12. Anegg U, Lindenmann J, Matzi V, Smolle J, Maier A, Smolle-Jüttner F Efficiency of fleece-bound sealing (TachoSil) of air leaks in lung surgery: a prospective randomised trial. Eur J Cardiothorac Surg. 2007;31:198-202.

13. De Leyn P, Muller MR, Oosterhuis JW, Schmid T, Choong CK, Weder W, et al Prospective European multicenter randomized trial of PleuraSeal for control of air leaks after elective pulmonary resection. J Thorac Cardiovasc Surg. 2011; 141:881-7.

14. Fabian T, Federico JA, Ponn RB. Fibrin glue in pulmonary resection: a prospective, randomized, blinded study. Ann Thorac Surg. 2003;75:1587-92.

15. Saito Y, Omiya H, Shomura Y, Minami K, Imamura H. A new bioabsorbable sleeve for staple-line reinforcement: report of a clinical experience. Surg Today. 2002;32:297-9.

16. Stammberger U, Klepetko W, Stamatis G, Hamacher J, Schmid RA, Wisser W, et al. Buttressing the staple line in lung volume reduction surgery: a randomized three-center study. Ann Thorac Surg. 2000;70:1820-5.

17. Roberson LD, Netherland DE, Dhillon R, Heath BJ. Air leaks after surgical stapling in lung resection: a comparison between stapling alone and stapling with staple-line reinforcement materials in a canine model. $J$ Thorac Cardiovasc Surg. 1998;116:353-4.

18. Amato MB, Barbas CS, Medeiros DM, Magaldi RB, Schettino GP, LorenziFilho G, et al. Effect of a protective-ventilation strategy on mortality in the acute respiratory distress syndrome. $N$ Engl J Med. 1998;338:347-54.

19. Kawamura M, Kase K, Sawafuji M, Watanabe M, Horinouchi H, Kobayashi K Staple-line reinforcement with a new type of polyglycolic acid felt. Surg Laparosc Endosc Percutan Tech. 2001;11:43-6.

20. Blaine G. Experimental observations on absorbable alginate products in surgery; gel, film, gauze and foam. Ann Surg. 1947;125:102-14.

21. Nunamaker EA, Purcell EK, Kipke DR. In vivo stability and biocompatibility of implanted calcium alginate disks. J Biomed Mater Res A. 2007;83:1128-37.

22. Qin Y. Ion-exchange properties of alginate fibers. Textile Res J. 2005;75:165-8.

23. Blair SD, Backhouse CM, Harper R, Matthews J, McCollum CN. Comparison of absorbable materials for surgical haemostasis. Br J Surg. 1988;75:969-71.

24. Smith JM. Promoters can insert naturally into DNA. In: Jaeger NJ, ed. Genetic roulette: the documented health risks of genetically engineered foods. White River Junction (VT): Chelsea Green; 2007.

25. Kawamura M, Sawafuji M, Watanabe M, Horinouchi H, Kobayashi K. Frequency of transmission of human parvovirus B19 infection by fibrin sealant used during thoracic surgery. Ann Thorac Surg. 2002;73:1098-100. 